\title{
Training Program in Reproduction, Early Development, and the Impact on Health (REDIH): Evaluation of Year 1
}

\author{
Dr. Colla J. MacDonald, ${ }^{1}$ Dr. Douglas Archibald ${ }^{1}$, \\ Dr. Jay M. Baltz ${ }^{1,2}$, Dr. Gerald M. Kidder ${ }^{3}$ and Dr. Hugh Clarke ${ }^{4}$ \\ University of Ottawa ${ }^{1}$ \\ Ottawa Hospital Research Institute ${ }^{2}$ \\ University of Western Ontario ${ }^{3}$ \\ McGill University ${ }^{4}$
}

Received: November 13 Accepted: December 7 Published: February 1, 2012

doi:10.5296/jse.v2i1.1077ＵRL: http://dx.doi.org/10.5296/jse.v2i1.1077

This research was supported with a grant from the Canadian Institutes of Health Research (CIHR) Strategic Training Initiative in Health Research (STIHR) program

\begin{abstract}
Objectives: The purpose of this research was to use the W(e)Learn conceptual framework to design, deliver and evaluate the Reproduction, Early Development, and the Impact on Health (REDIH) training program for graduate students and postdoctoral fellows.

Methods: The REDIH program provides stipends and other support, and runs semi-annual two-day face-to-face training sessions for trainees with their mentors. During the sessions, seminars and workshops are provided, and laboratory visits are arranged for trainees. A mixed methods approach (surveys and focus groups) was used to evaluate the content, delivery, structure and service of the first year of the REDIH training program.

Results: Trainees recognized and appreciated three main improvements implemented into the second REDIH training session as a result of their feedback: (a) objectives and expectations were made clearer, (b) laboratory visits and more hands-on learning had been implemented, and (c) segregation between trainees and mentors had been greatly reduced. Trainees also had several recommendations for further improvements.
\end{abstract}

Conclusions: Trainees were overwhelmingly appreciative of and grateful for the opportunity to be involved in the REDIH project. Trainees felt their voices had been heard during the first 


\section{Macrothink}

training session and steps were taken to address their expressed concerns and needs in the second session. This study also demonstrated that evaluation is critical for program design, improvement and long-term success. Perceptions of quality were strongly linked to a fit between participants' experiences, needs, wants, and perceived competencies; a formal evaluation process; and project administrators and the curriculum committee respecting and responding to the participants' feedback via the evaluators.

Keywords: Reproductive Medicine, Training Program 


\section{Introduction}

In 2008, in response to a request for applications from the Canadian Institutes of Health Research (CIHR) Strategic Training Initiative in Health Research (STIHR) program, a training program in Reproduction, Early Development, and the Impact on Health (REDIH) was proposed by researchers specializing in biomedical, clinical, population health and ethics research from six collaborating Universities in Quebec, Ontario and Health Canada. The project received funding for six years starting in mid-2009. The purpose of the REDIH program is to provide training in reproduction and early development for graduate students, postdoctoral fellows, and clinician-scientists in order to develop the next generation of reproductive biologists in Canada and to move the field forward. This training is meant to be supplementary to the trainees' graduate or postdoctoral training programs, specifically exposing REDIH trainees to a broader range of methodologies, including basic biomedical, clinical, population health, and ethics research addressing questions in the field, to place their research in a broader societal and health context, and to promote professional development geared to the various careers in this field.

Semi-annual training sessions for mentors (university faculty and federal government research scientists; experienced researchers) and trainees (M.Sc. and Ph.D. students, and postdoctoral fellows; researchers in-training) will be the main venues for the presentation of diverse training modules (workshops in presentation skills, peer review and writing skills, knowledge translation, regulatory issues, careers in industry, ethics, to name a few). This paper reports the findings of the evaluation of the first year of the REDIH six-year program, concentrating on the semi-annual meetings. The findings will inform changes to the REDIH program in the remaining years. However, the findings may also be applicable to a wider audience: to inform other professional programs currently using a mentor/trainee program similar to REDIH, or for programs that may want to adopt one.

\section{Rationale for REDIH}

Research in reproductive biology and early development has had a profound impact on improving human health, as highlighted by the recent full issue of Nature Medicine devoted to Reproductive Biology (Introduction, 2008). Through research, reproductive medicine has become increasingly successful but also increasingly technologically and ethically complex, particularly in the field of assisted reproductive technologies (ART). Over ten percent of reproductive-age Canadian couples suffer from infertility (Ledger, 2009; Gnoth et al., 2005; Natale, Paliga, Beier, D'Souza, \& Watson, 2004). ART has been very successful at treating infertility and the demand for ART-based treatments such as in vitro fertilization (IVF) and intracytoplasmic sperm injection (ICSI; Alukal \& Lipshultz, 2008) is likely to increase as couples in developed countries are choosing to delay childbearing until later in life. However, ART is associated with a possible increase in birth defects (Hansen, Kurinczuk, Bower, \& Webb, 2002) and has clearly resulted in a large increase in multiple gestation pregnancies with associated morbidity (Sutcliffe \& Ludwig, 2007). In addition, there is increasing evidence that perturbations of gametes and early embryos affect the health of the fetus and placenta and even of offspring into adulthood (Fleming et al., 2004; Doherty, Mann, 
Tremblay, Bartolomei, \& Schultz, 2000; Fleming et al., 2004; Fortier, Lopes, Darricarrere, Martel, \& Trasler, 2008; Mann et al., 2004). Thus, there are unanswered questions about long-term safety. Of clear concern, therefore, is that the application of ART has preceded a full understanding of possible health effects (Alukal \& Lipshultz, 2008; Hansen, Kurinczuk, Bower, \& Webb, 2002; Nair, 2008). Moreover, similar health concerns have been raised about reproductive effects of environmental toxicants (Barr, Bishop, \& Needham, 2007; Fraser \& Adeoya-Osiguwa, 2006; Wen et al., 2006) and the emerging role of reproductive medicine in oncology as young patients seek to preserve fertility (Brannstrom \& Milenkovic, 2008). To help sustain and expand Canada's position at the forefront of research in reproduction and early development, rapidly translate research into the clinic, navigate ethical and regulatory complexities, and increase our knowledge of how to avoid risks of adverse health consequences, a new generation needs to be trained to work in research, the clinic, industry, the nonprofit sector, governmental agencies, and as decision makers, REDIH has been implemented to help address these needs.

\section{Summary of the first year of the REDIH Program}

Eleven trainees participated in the first year of the program. In subsequent years this will increase to approximately 22 trainees. However, in the first year of STIHR, programs start-up funding of half the subsequent annual level was provided by the funding agency. Therefore, in the first year only eleven trainees were funded. Trainees were selected for REDIH through a competitive process, after already having been accepted for graduate or postdoctoral training by mentors who are members of REDIH. Trainees and mentors from the participating universities were brought to a central location for two semi-annual face-to-face training sessions held with trainees and mentors (January 25-26 and May 20-21, 2010). Mentor and trainees travel expenses were covered by the REDIH project. The sessions ran from 9:00 AM-5:00 PM for two days with a networking dinner held at a local restaurant for all trainees and mentors during the first evening.

During the first training session (January, 2010), trainees each presented their research areas, two workshops/modules were presented and evaluated (Science with Impact, and Social Determinants of the Health of Embryos), and there were two presentations by REDIH mentors (Knowledge Translation in Human Reproduction, and Fertility Preservation). In addition, focus-group interviews were held with groups of trainees and a group of mentors (see Methodology section for more details).

In the second training session (May, 2010) the first day consisted of participation in a scientific meeting (the 2010 Ottawa Reproductive Biology Workshop) consisting of presentations by REDIH mentors and other faculty and trainees and posters of trainees' research topics. On the second day, lectures in Assisted Human Reproduction and Prenatal Diagnosis were presented, coupled with tours of an assisted human reproduction clinic and human embryology laboratory, and the neonatal intensive care unit at a hospital. The workshop, lectures, and site visits were evaluated via surveys and focus-group interviews were held with both trainees and mentors. 


\section{Research Questions}

The following overall research questions served as a guide for the evaluation of the REDIH program:

1. How did trainees react to the learning experiences?

2. Did trainees acquire new knowledge and skills regarding reproductive and early developmental biology and health?

3. Was there a change in trainees' attitudes towards the value and use of fostering and strengthening interdisciplinary, inter-pillar Canadian research teams?

4. Did trainees transfer knowledge through embedding $\mathrm{KT}$ in the research projects, and interactive teaching?

\section{W(e)Learn}

The W(e)Learn framework (MacDonald, Stodel, Thompson, \& Casimiro, 2009; Casimiro, MacDonald, Thompson, \& Stodel, 2009) was used as a guide to design, deliver and evaluate the REDIH program. W(e)Learn outlines four critical dimensions of educational programs - structure, content, media, and service-and is grounded in socioconstructivist theories (Dirkx, 2001; Salomon \& Perkins, 1998; and interprofessionalism (Barr, Koppel, Reeves, Hammick, \& Freeth, 2005; Meads \& Ashcroft, 2005; Oandasan et al., 2004. W(e)Learn constructs also provided the framework to create the evaluation questionnaire.

W(e)Learn has been used to guide the design, delivery and evaluation of several healthcare training programs including ePhysicianHealth and eWorkplaceHealth. These programs were developed to help physicians and other healthcare professionals improve their health and well-being (MacDonald et al., 2011; Puddester, MacDonald, Archibald, Sun, \& Stodel, 2010). In addition, W(e)Learn was used to guide the design, deliver and evaluation of Teams of Interprofessional Staff (TIPS) project designed to provide interprofessional education to practicing healthcare professional who were engaged in specific clinical initiatives as an interprofessional team (MacDonald, Archibald, Puddester, \& Bajnok, 2011).

\section{Methodology}

\section{Research Approach}

A concurrent parallel mixed methods approach was used to evaluate the first year of the REDIH training program (Creswell \& Plano Clark, 2001; Pluye, Gagnon, Griffiths, \& Johnson-Lafleur, 2009). Using a mixed methods approach, where qualitative and quantitative techniques are combined, is becoming increasingly popular (Collins, Onwuegbuzie \& Jiao, 2007). Indeed, under the right circumstances, a mixed methods approach can provide a better understanding of the problem than either research approach alone (Creswell, 2009). Both quantitative and qualitative methods, however, have distinctly different philosophical roots (McMillan \& Wergin, 2006). The challenge therefore is to create a design that provides the optimal combination and sequence of both approaches. 
In a mixed methods approach, quantitative and qualitative data were collected and analyzed concurrently to obtain a full understanding of the participants' perceptions of the REDIH program. This method offsets the weaknesses and complements the strengths of the quantitative and qualitative research approaches (Bryman, 2007; Creswell \& Plano Clark, 2011; Johnson \& Onwuegbuzie, 2004). The quantitative survey results have been integrated or triangulated with the qualitative themes that emerged from the focus groups to provide more robust evidence.

\section{Qualitative Data Collection}

During the first training session in January 2010, three focus-groups were conducted by the REDIH program evaluator and her PhD trainee; two with trainees and one with their mentors (samples of the focus-group questions can be found in Appendix A). The first focus-group consisted of five trainees and the second group consisted of four trainees (one trainee was absent during the focus-group and one trainee was on maternity leave). In total, the two trainee focus-groups included three M.Sc. students, three Ph.D. students, and three postdoctoral fellows. The purpose of the focus-groups during the first training session was to (a) supplement the information obtained from the surveys on the workshops presented, (b) obtain an indication of personal and professional needs and program expectations, and to (c) obtain a baseline of trainees' and mentors' perceptions and attitudes at the beginning of the program.

During the second training session in May 2010, two focus-groups were conducted. One focus-group was composed of three female and two male mentors. The second focus-group consisted of ten trainees (six females and four males). The information from the focus-groups during the second REDIH training session was used to triangulate the findings from the surveys and to make comparisons to the first REDIH training session.

\section{Qualitative Analysis}

Each interview was audio-taped and then transcribed verbatim. The transcripts were checked for accuracy by the researcher listening to the audio recording (mp3 file) and comparing it to the transcribed text. Open coding of the text was then performed by hand. After a preliminary list of codes was developed the transcripts were coded a second time. The coding process consisted of grouping the common codes together to form themes and sub-themes based on the W(e)Learn framework. The coding was reviewed several more times to ensure no new codes emerged from the data. Two researchers analyzed the interview data separately and compared results to increase the rigor of the analysis (one was the program evaluator and the other was her $\mathrm{PhD}$ trainee).

\section{Quantitative Data Collection and Analysis}

The constructs of the W(e)Learn framework (content, delivery, service, structure and outcomes) also guided the data analysis of the REDIH Training Module Assessment survey (See Appendix B). The surveys were administered directly after each workshop, lecture, or site visitation during both of the semi-annual training sessions. Descriptive statistics and response frequencies were use to assess the trainees' experiences. 


\section{Findings}

\section{Focus Groups}

Findings from the focus-groups during the first and second training sessions provided in-depth insights into the trainees' perceptions on and suggestions for the REDIH program. In addition, the mentor focus-groups allowed mentors to contribute their ideas on the state of the REDIH program as well as suggestions for future directions. The following themes re-occurred during the REDIH focus-groups at the first and the second training sessions: Objectives of the REDIH Program, Learning Environment, Selection of REDIH Participants, and Laboratory Visits. In addition, the following new themes emerged during the second REDIH training session: Opportunities, Sharing the Evaluation Report, Transfer of Learning, and Planning the REDIH Training Sessions. All of these themes will be elaborated upon in the ensuing sections.

\section{End of Module Surveys}

There was a range of sample sizes for each training module, from a minimum of seven to maximum of ten trainees, consisting of those who completed the Module Assessment Survey Results for all the training modules during the first year of the REDIH program. One trainee was absent for the first training session, and others were present for the second training session modules but did not submit their surveys (Reproductive Biology Workshop, N=9; Neonatal ICU Hospital Tour, $\mathrm{N}=7$ ).

It should be noted that responses on items of the survey "not applicable" and "undecided" were excluded from the mean score calculations. In the reporting of the data for the first and second training session they were included. Non-applicable responses were assigned a value of " 0 " and undecided a value of " 6 ". Although the inclusion of these responses skewed the results, it did show that certain items on the Module Assessment Surveys should either be removed or module presenters did not take certain criteria into consideration when planning. For example, in all the training session modules, the item "readings were relevant," and "resources were relevant and applicable" were often considered not applicable because module presenters did not provide readings or resources. This noted result suggests that either the items should be deleted from the survey or module presenters should be told to include readings and resources with their presentations. Summary statistics of the modules are found in Table 1. 


\section{Macrothink}

Table 1. Mean Scores on the W(e)Learn Constructs for each session activity*

\begin{tabular}{|lll|}
\hline Activity & W(e)Learn Construct & Mean (SD) \\
\hline Science with Impact & Structure & $4.50(.72)$ \\
& Content & $4.21(.86)$ \\
& Media & $4.55(.66)$ \\
& Service & $4.78(.68)$ \\
Ethics of Embryos & **Outcomes & $3.16(.71)$ \\
& Structure & $4.54(.73)$ \\
& Content & $4.43(.71)$ \\
& Media & $4.55(.60)$ \\
& Service & $4.55(.61)$ \\
& $* *$ Outcomes & $3.50(.68)$ \\
Reproductive Biology & Structure & $4.36(.70)$ \\
& Content & $4.19(1.01)$ \\
& Media & $4.40(.78)$ \\
& Service & $3.96(1.19)$ \\
& $* *$ Outcomes & $2.94(.78)$ \\
Fertility Clinic Visitation & Structure & $4.91(.30)$ \\
& Content & $4.62(.70)$ \\
& Media & $4.45(.98)$ \\
& Service & $4.91(.59)$ \\
Neo-natal Hospital Tour & **Outcomes & $3.81(.46)$ \\
& Structure & $4.93(.27)$ \\
& Content & $4.80(.52)$ \\
& Media & $4.79(.36)$ \\
& Service & $4.81(.18)$ \\
& $* *$ Outcomes & $3.67(.58)$ \\
\hline
\end{tabular}

Note. Response options: 0 = not applicable; $1=$ never; 2 = rarely; $3=$ sometimes; 4 = often; 5 $=$ always; $6=$ undecided

*Responses of not applicable and undecided were treated as missing data and are not reflected in the calculation of means

**Response options: $0=$ not applicable; $1=$ strongly disagree; $2=$ disagree; $3=$ agree; $4=$ strongly agree; 5 = undecided

\section{Reoccurring Themes}

\section{Objectives of the REDIH program}

During the focus-groups at the first REDIH training session, trainees reported they did not have a clear understanding about what the objectives of the REDIH program were or should be. One trainee remarked, "Even when I was applying for this scholarship I knew nothing about it, what to expect”. Trainees recommended that more information regarding what to expect and what would be expected be provided prior to arriving at the first training session, 
and stated that this would be appreciated and helpful. Although trainees said they were uncertain of the objectives, they had very clear ideas of what they hoped to obtain from the REDIH experience. They stated they wanted an opportunity to network, develop communication skills, observe what was happening in other labs, learn new techniques and skills, and get a broad sense nationally, internationally and globally of reproduction research and related fields. One trainee reported that public speaking should be one of REDIH's objectives:

I would like to be able to learn to do a bit more public speaking, how to speak in front of an audience of people, presentation and communication skills. The one yesterday seemed to drag on a long time and didn't seem very specific to what I needed it for.

A second trainee reported he felt networking and visiting other researcher's labs should be objectives of REDIH:

There is a group of early staged researchers involved in male reproduction. We started a network where we would actually visit other labs....I hope REDIH will provide us with that opportunity too. To do that we need to learn how to network and that is something I hope to learn.

During the first REDIH training session, the mentors had very explicit ideas of what they felt the objectives of the REDIH program should be. The mentors had high expectations for the program in general, including a global objective of fostering and developing the next generation of reproductive biologists in Canada who would move the field forward. They felt the learning objectives should depend upon the training level of the trainees in (M.Sc., Ph.D., or Postdoctoral Fellow). Mentors also agreed the main objectives should include transmitting what research is all about, why we do it, what is special about research, and the discovery process. During the Mentor focus-group interview during the first REDIH meeting, when asked what the learning objectives of the program should be, one Mentor stated,

I think the objectives of REDIH are to develop inter lab communication, to broaden the knowledge skills, and the knowledge possibilities of our trainees at every level, graduate and postdoctoral, to learn what is going on in related fields, to have them get dimensions that they could not get from our lab just working with us, but by having them learn from other students and also from other mentors.

During the focus-groups at the second training session four months later, one mentor emphasized that REDIH is in the first of six years of operation. Although he felt they had a general idea of what the program's objectives and expectations should be, he believed it would take time to know what was realistic and what was best for all stakeholders involved. One mentor shared:

...this is a new program. I don't know if it is possible to be completely specific at the beginning what precisely we want and we want the trainees to get out of it. We have to see what are realistic objectives and what are realistic expectations and I think it takes a certain amount of time. 
Another mentor confessed she was extremely involved in the development of the program and from her perspective very clear on what mentors wanted for and from trainees. She also suggested perhaps the mentors could have done a better job of communicating with the trainees. In her words:

I think the [purpose] of developing the website is to put more materials on there so trainees have some sense of our overall plan for them. I think because the website is not up yet, I don't imagine the situation has changed between January and now.

A mentor shared that one effort the REDIH program organizers had made in response to trainees expressed needs regarding objectives and expectations, was to change the application form sent to applicants in the second round. He explained:

One concrete thing we have done is .... description of the program has been sent out. So as part of the application, they should have seen them [objectives and expectations]. New mentors also applying are also getting the description... but I think that we are still waiting for the website for there to be universal accessibility.

During the focus-group at the second REDIH training session, trainees reported noteworthy improvements had been made since the first training session with respect to communication of explicit program objectives and expectations. Moreover, trainees recognized and appreciated the fact that organizers had responded to their expressed concerns and needs reported during the first REDIH evaluation report. One trainee stated:

Last time we were not really sure what was going on. But I think our comments from the last session were really taken in and this time around, I think this is absolutely fantastic. I really feel, especially today, right from start to finish. Everything is really good!

Another trainee acknowledged the changes in the application form and noted how much clearer things were as a result. He commented, "I think the new application form ....in my mind is clearer about what they actually wanted to deliver. I think the additional document [they included] is helpful”.

\section{Learning environment}

Although the trainees' overall perceptions of the atmosphere during the first REDIH training session were positive, they emphasized that discussions were dominated by the mentors. They observed an obvious segregation between mentors and trainees. Trainees repeatedly and consistently expressed a genuine desire to get to know mentors better and learn more about their expertise. They suggested it would be beneficial to have more time to network with other trainees and mentors both informally and formally. A mentor also recommended providing trainees with more free time to get to know one another. Trainees believed a lot of networking with other trainees and mentors could take place online and proposed creating a biography or a web page on each trainee and mentor to share among the REDIH participants. Trainees suggested the mentors make presentations perhaps with their trainee on their research. 
Trainees suggested setting up a learning environment that was more inclusive and where mentors made more of an effort to solicit input from the trainees. One Ph.D. trainee expressed her thoughts on this issue:

Although I found it very engaging being there and listening, I felt like it was almost the mentors taking over. Although it was great to hear what they had to say I couldn't really join in. I could listen and hopefully assimilate what they were saying, but I couldn't put my own thoughts into it.

Trainees pointed out that although they did not feel it was intentional, and they recognized that the mentors appear to enjoy one another and want to spend time together, there was an obvious segregation between mentors and trainees.

In the focus-group during the second training session, mentors upheld that in the first session as in the second, trainees were free to provide comments and address and/or ask questions. However, one mentor suggested, "Perhaps we need to encourage them to get involved a little bit more to take advantage”.

Another mentor informed the group that, unlike the first dinner where the trainees and mentors sat at different tables, in an effort to address the segregation issue, the second training session dinner would have designated seating with intentional distribution of mentors and trainees at the same tables.

The trainees appreciated the effort made by REDIH organizers to address their concerns regarding segregation. Trainees commented on the seating plan at dinner during the second training session:

I think that it was also better last night than in January. So it was nice to have, you know, a table of seven rather than a table of four. So I think that it was a little more structural and also it was enforced seating [laughter].

A second trainee confirmed that the seating plan in the second session was a nice mix of mentors and trainees and the large round tables facilitated discussion. Another trainee pointed out that the second session was better due to the fact that they already knew people which made it more comfortable to initiate conversations. When asked what the most rewarding aspect of the second training session was, one trainee commented without hesitation: "Dinner last night. I liked the food and I liked the communication and interaction”.

The quantitative results of the surveys also supported the findings of the learning environment theme. Overall, trainees were very pleased with the modules offered. However, The outcomes construct of the surveys for the Science with Impact and the Reproductive Biology Workshop were rated lower than the other modules. Moreover, these two modules were openly criticized by the trainees during the focus-groups.

\section{Selection of REDIH participants}

At the first January focus-group some trainees discussed that the program should include more social science researchers. 
I am not sure if that is outside of the group's aim or if it just happened to be that the group that knew each other were all lab scientists...or even longitudinal studies about the effect of IVF or the various things happening in the lab. It would be neat to have that extra breadth of expertise included.

One student who did not work in a laboratory suggested the selection committee consider choosing at least two researchers from the same discipline when deciding on trainees for the program. She was the only non-laboratory trainee in the program and stated she would feel more comfortable if there were a couple of other trainees with similar research interests as hers.

I am really interested in the process, activities and research ethics...Maybe we could have some sub-groups of the basic science and ethics and interact together. Or not have any. I don't want to say eliminate me but a lot of the time I am lost when listening to the more science presentations.

Trainees agreed both laboratory researchers and non-laboratory researchers need to work together and could benefit by learning more about each other in the REDIH program.

Another trainee who was a laboratory researcher thought it was important to add a variety of related researchers. "I really liked the perspective today on the ethical side of things and I really like the way you think and see things. Having variety is a lot better than excluding”.

Trainees also indicated that there seemed to be a dominance of mentors and trainees conducting research on female reproduction in the REDIH program. A couple of trainees suggested having a better balance. One trainee pointed out that he didn't see a big difference between the male and female:

In my brain the oocyte is not that much different from sperm because we all have the same goal. I could replace the word oocyte for sperm. So for me that is not really a big deal ....because it is not about the science behind it but the way to get there.

One trainee provided a rationale for having a dominance of female reproduction research represented in the program:

I do understand that we should be balanced on male and female [research]. But there is the dominance of the oocytes during the fertilization. So we are more focused on the oocytes than sperm and that is understandable. Today quite a few speakers spoke on each and I think it has been balanced already.

During the second training session, mentors responded to the trainee's concern suggesting it was important to have a balance of researchers who study both male and female reproduction so everyone feels very much part of the program. Currently, the program has mostly female reproduction researchers. However the mentors acknowledged there is a small group whose research focused more on male reproduction research. One mentor suggested an effort needed to be made to make everyone feel they belong. "Including them will also be a challenge. So they don't have the feeling they are not part of it. So we should include everybody”. 
Similarly, another trainee suggested having more people from various areas. "I don't know how you guys are choosing [trainees but] make it a little more equal ...some people in biology, ethics, or more clinical work". Another trainee said he found it interesting to see what other people do in their laboratories.

\section{Laboratory visits}

Trainees stated in the focus-groups at the first training session that laboratory visits would broaden their understanding of and knowledge and skills in the field of reproductive research by exposure to others' research. Trainees voiced a strong desire for hands-on approaches and to see 'research applied' in the workplace: One trainee stated, "They [presenters] showed a variety of strategies but ...maybe we could visit not only the fertility center but also other labs and universities". Trainees suggested including a 'shadowing learning experience' in various labs for half a day in each REDIH session. They articulated that experiencing clinical situations would be extremely beneficial to their career development. One Ph.D. trainee elaborated:

I would like more hands on approaches manipulating embryos and more opportunity to go to IVF clinics to see how it is done in a real lab setting rather than being in my one lab doing my one set of procedures.

During the second training session, REDIH organizers responded to the trainees' request from the first evaluation report by organizing a half-day in one of the mentor's laboratories - the clinical embryology laboratory of the human infertility clinic, coupled with a trip to the neonatal intensive care unit to appreciate the types of health problems that can arise in newborns. One trainee explained:

Tomorrow is the first time trainees are going on-site to the fertility centre. They will go to the hospital and come to clinic. This might start to break the barrier of just having to think about their own research and will get them used to looking into other areas.

The trainees were excited and appreciative of the site visits during the second training session. One trainee exclaimed, "Yesterday was fabulous with [the mentor]. She should be recognized for all the work she has put in. It was tremendous!

When asked what they felt was the most rewarding aspect of the second training session a trainee said it was the day in the clinical laboratory. "For me it was this morning because I am working on cows' stimulation and ovaries....but to do the application, see the application...and having the opportunity to ask direct questions to [the mentor] was fantastic!”

These findings are corroborated by the results of the surveys (See Table 1). The results show slightly higher scores for the fertility clinic session and visitation, and the neo-natal session and floor visitation. These scores reflect the sentiment expressed by the trainees that they want more laboratory visits and hands-on learning.

\section{Presentations}

Trainees expressed in the first focus-group that they would appreciate more time to present their research and have the opportunity to receive feedback from both the mentors and other 
trainees. One trainee recommended: ... rather than starting the training sessions with five minute presentations from trainees to quickly tell each other what we are doing, and then dive into everything else, we could have had a meeting like this at the start for everyone to discuss what we were expecting or hoping for.

When asked what the least rewarding aspect of the second REDIH training session was one trainee who did a presentation mentioned he was very disappointed with the technical issues with the projector as it affected his presentation. The result was that it was not very clear to show the fluorescence images.

During the second training session in May, two trainees were given the opportunity to present their research to the group for approximately fifteen minutes each. One mentor commented on the presentations: "I thought both trainees had excellent presentations. I don't know whether the presentations are valuable to the trainees. I think we have to ask the trainees”.

A second mentor reported she would have preferred to allocate even more time for the trainees' presentations. She suggested the extra time would provide the opportunity to obtain the following types of information: "How trainees respond to the findings was not brought out at all. How did the postdocs get involved in those studies... What are the opportunities for study in this area if you were to choose it”?

One trainee suggested the poster presentation at the second training session could be one venue to achieve awareness of other research in the field. One trainee expressed her disappointment with the organization of the poster session and the lack of communication regarding judging the posters.

I found the posters session yesterday was somewhat of a shamble. I had no idea they were going to mark it and then felt all kind of anticipation of competition....Then we were told to stand there, but no one came to look at the posters.

Apart from not knowing that the poster presentations would be judged, the trainees were very receptive to the idea of the poster presentation. However, a trainee stated that the scheduling of these presentations should not be presented during the lunch break. This was because the presenters had to stand beside their posters and missed their lunch.

A mentor suggested another way to get trainees learning, involved and interacting could be to organize round table discussions during the workshops. She described:

...you take a topic...like ovarian cancer....throw it on the table and ask them to identify some of the issues that need to be addressed in research that apply to any discipline. There would be all sorts of questions to align within the topic and force them to think outside the box and outside their views of the same techniques that apply to their fields....

The findings related to the presentation theme are also supported by the results of the surveys. The outcomes construct of the Reproductive Biology Workshop were rated lower than the most other modules. Moreover, this module was openly criticized by the trainees during the focus-groups because either the presentations were not relevant to their work, or they were 
too long. The trainees rated this module as 'agree' regarding achieving learning outcomes whereas most other sessions were all rated slightly higher; closer to 'strongly agree'.

\section{New Themes}

\section{Opportunities}

At the second training session, mentors stated they felt trainees had an advantage and would have a 'leg up' with regard to funding and workplace opportunities. One mentor shared:

The trainee funded from my lab, has worked very well because the funding he received from this provided the opportunity to take advantage and apply for another large scholarship he has been awarded. So it is to ensure that these trainees have a leg-up into larger full-scale fellowships and scholarships while in our hands...

Another mentor reinforced what a trainee suggested during the January focus-group - that the REDIH program committee needs to provide more opportunities for trainees between training sessions. Some of the mentor's ideas included:

We need to trade people between labs... and have modules happening in between training sessions. We can't just get together twice a year ...with nothing running in between. That's going to be a challenge. It is much easy to get people to come for a couple of days to do something than it is to have 20 or 30 different people or different labs all doing this all year.

\section{Sharing the evaluation report}

One finding that emerged during the second training session was that the 50-page evaluation report from the first training session had not been shared with all the mentors or trainees. The second training session focus-group may have been richer had the mentors and trainees been privy to the information in the report before they took part in the second interview. One mentor commented on this oversight:

I think that it [the REDIH program] has been working fine. As somebody said...it's hard to tell ... for things that we haven't yet rolled out how they are going to work. But the [first] meeting was good and I think that we learnt some lessons from the evaluation which we have not shared yet. ... it [the evaluation] is an ongoing way of improving the program.

\section{Transfer to the workplace}

During the second training session, trainees were asked if they had a chance to implement anything they had learned from the first REDIH training session in their workplaces. One trainee shared that every week they have a discussion on various topics at his laboratory. After the first training session where a presentation had been made on ethics, this trainee reported he talked about ethics at their weekly meeting. "I talked about ethics. We all work in our laboratories in embryo development. Life decisions...but we never really discuss the ethics component...” 


\section{Planning the REDIH training sessions}

A trainee said the timing of the May sessions was a disappointment. It was a long week-end and by the time the date was chosen, she had already made plans to travel. The time of the REDIH sessions should be set up a year in advance so everyone can plan their schedules ahead of time. One trainee revealed:

I think my least rewarding thing ... is the timing ....I [had planned] to go to Boston for this long weekend. I put that on hold and changed that. I didn't want to miss out obviously on this day. I really didn't like this because I made my [Boston] plans ages in advance.

Another trainee suggested that the program should send the applications to trainees re-applying directly as opposed to via their mentors.

Maybe send the re-application to students [directly]. Because my supervisor did not send it on to me. So I got the reminder email the day before it was due. I said, oh! Because he [my mentor] just read the email [as if] he should review the application and see how it had changed. He didn't think he had to send it on. So ... I'm glad that a reminder email was sent [chuckles].

\section{Discussion}

Overall, trainees expressed they were overwhelmingly appreciative of and grateful for the opportunity to be involved in the REDIH program. Moreover trainees felt their voices had been heard during the first training session and steps were taken by the program organizers and the curriculum committee to address their expressed concerns and needs.

\section{Three Main Improvements}

Trainees recognized and appreciated three main improvements during the second training session: (a) objectives and expectations were made clear; (b) laboratory visits and more hands-on learning had been implemented, and (c) segregation between trainee and mentors had been greatly reduced. Trainees were extremely happy with improvements with respect to communication of explicit program objectives and expectations. Trainees were thrilled with the laboratory visit and the addition of more hands on activities. Finally, trainees were grateful for the efforts made to increase the integration between trainees and mentors.

\section{Additional Improvements}

Additional efforts that had been addressed were providing more 'down time' for networking. Moreover, during the first evaluation, trainees asked for more than five minutes to present their research and attain feedback. Two trainees were provided fifteen minutes to present their research at the second training session. However, both mentors and trainees expressed that in the future, additional time should be added for questions and feedback.

\section{Recommendations for Future REDIH Sessions}


Both trainees and mentors reported they were happy with the way things were going with the REDIH program. However, both trainees and mentors acknowledged it was 'early in the game' and more time was needed to figure things out completely. Since the second session was completed, the website has been developed and should facilitate communication and networking. Moreover, only so many suggestions can be addressed in one training session and it is expected that many of the other recommendations from the first evaluation report will be addressed in the trainees' second year of the program.

For example, trainees felt specific training would help them attain their career goals: writing skills; communication skills; feedback; laboratory visitations; teaching; and logistics. Trainees repeatedly stated they would like to develop skills in writing research grant proposals, preparing cover letters for grant applications and interviews, and writing travel grant applications for attending conferences. Similarly, they reported they would appreciate assistance with writing academic papers and reports. Mentors also stated they felt workshops should be offered on both effective communication and publication processes.

The communication skills trainees said they needed included learning how to: talk about their research to people from other disciplines; speak to the media; write a press release; and craft a 150 word abstract. Trainees felt it would be helpful to see the mentors present their work in order to be exposed to the mentor's areas of expertise, and learn from them with regard to presentation skills and public speaking.

Trainees expressed they would appreciate the opportunity to present their research and have the opportunity to receive feedback from both the mentors and other trainees. Trainees suggested organizing special interest groups to follow-up with ideas and issues between the organized REDIH training sessions. Some trainees said they thought learning about how to design a course curriculum, learning objectives and learning outcomes would be a beneficial workshop. Trainees reported they want to understand the logistics of running a lab and obtain a better knowledge of the business aspects behind a research lab.

Trainees suggested it would be beneficial to have more time to network with other trainees and mentors both informally and formally. They believed a lot of networking with other trainees and mentors could take place online and proposed creating a biography or a web page on each trainee and mentor to share among the REDIH participants. Finally, trainees suggested that the mentors make presentations to the group and perhaps with their trainee on their research.

Trainees felt it was essential that the program content be relevant and catered specifically to their specific needs and situations. Trainees were in agreement that the program should focus on identifying potential issues that will arise in their careers.

Some trainees thought it was important to establish whether the aim of the REDIH program is to learn how to conduct research for lab researchers or 'research' from a broader perspective. Trainees agreed they would enjoy being exposed to a variety of directly related topics they would be facing in the future. 
Trainees pointed out that there seems to be a dominance of mentors and trainees conducting research on female rather than male reproduction in the REDIH program. Mentors acknowledged it is important but would be a challenge to make everyone feel included.

\section{Conclusions}

In conclusion, from the perspective of both the trainees and mentors, the REDIH program appears to be a success thus far. The program organizers and researchers deserve much credit for bringing it into fruition. It is apparent there is a great need for such training. Based on the findings from the comprehensive evaluation, several of the concerns and suggestions outlined in the first evaluation report have been addressed in a timely fashion. It is early in the program and it will take time and the second year of the training program to address all of their desires and needs.

The findings and discussion should be considered in the context of both the constraints imposed by early stage (first year of a six year project) and the complexities resulting from the heterogeneity of the cohort participating in the evaluation (diverse educational levels MSc. to Postdoctoral Fellows) and career experience (student to experienced researchers). The recommendations (Appendix C) proposed in this report are presented as next steps for improving and refining this pilot program as well as opportunities for follow-up initiatives.

As there have only been two REDIH training sessions to date (January and May, 2010) it was not anticipated that we would be able to answer research questions 4 on knowledge translation. There were however, some instances of knowledge translation that did emerge from the trainee interviews. Subsequent training session focus-groups will be used, along with the Training Program Module Assessment survey to evaluate the REDIH training program in the remaining five years of the program. Hopefully, in future reports we will be able to comment much more on knowledge transfer, as returning trainees may have had more opportunity to apply new behaviors, skills and attitudes. In at least two other studies (Allen, Sargeant, Mann, Flemming, \& Premi, 2003; Mann, Sargeant, \& Hill, 2009) found that healthcare professionals may be unclear about how to apply new learning immediately after the completion of an educational training session, "and may require time in practice to enable its internalization and assimilation” (Mann et al., p. 161).

\section{References}

Allen, M., Sargeant, J., Mann, K., Fleming M., \& Premi J. (2003). Videoconferencing for practice-based small group continuing medical education: feasibility, acceptability, effectiveness and cost. Journal of Continuing Education in the Health Professions, 23, 38-47. http://dx.doi.org/10.1002/chp.1340230107

Alukal, J.P. \& Lipshultz, L.I.(2008). Safety of assisted reproduction, assessed by risk of abnormalities in children born after use of in vitro fertilization techniques. Nature Clinical Practice Urology 5, 140-150. http://dx.doi.org/10.1038/ncpuro1045 
Barr, D. B., Bishop, A., \& Needham, L. L. (2007). Concentrations of xenobiotic chemicals in the maternal-fetal unit. Reproductive Toxicology, 23, 260-266. http://dx.doi.org/10.1016/j.reprotox.2007.03.003

Barr, H., Koppel, I., Reeves, S., Hammick, M., \& Freeth, D. (2005). Effective interprofessional education: Argument, assumption and evidence. Malden, MA: Blackwell Publishing. http://dx.doi.org/10.1002/9780470776445

Brannstrom, M. \& Milenkovic, M. (2008).Advances in fertility preservation for female cancer survivors. Nature Medicine,14, 1182-1184. http://dx.doi.org/10.1038/nm1108-1182

Bryman, A. (2007).Barriers to integrating quantitative and quantitative research. Journal of Mixed Methods Research, 1(1), 8-22. http://dx.doi.org/10.1177/2345678906290531

Casimiro, L., MacDonald, C. J., L., Thompson, T-L, \& Stodel, E. J. (2009). Grounding theories of W(e)Learn: A framework for online interprofessional education, Journal of Interprofessional Care, 23(3), 1-11. PMid:19142777

Collins, K.M.T., Onwuegbuzie, A.J. \& Jiao, Q.G. (2007). A mixed methods investigation of mixed methods sampling designs in social and health science research. Journal of Mixed Methods Research. 1, 267-294. http://dx.doi.org/10.1177/1558689807299526

Creswell, J. W. (2009). Research design: qualitative, quantitative and mixed methods. Thousand Oaks, CA: Sage publications.

Creswell, J. W., \& Plano Clark, V. L. (2011). Designing and conducting mixed methods research (2nd ed.). Thousand Oaks, CA: Sage.

Dirkx, J.M. (2001). The power of feelings: Emotion, imagination, and the construction of meaning in adult learning. In S.B. Merriam (Ed.), New directions for adult and continuing education: Vol. 89. The new update on adult learning theory (pp.63-72). San Francisco: Jossey-Bass Publishers.

Doherty,A. S., Mann, M. R., Tremblay, K.D., Bartolomei, M.S., \&Schultz, R.M. (2000). Differential Effects of Culture on Imprinted H19 Expression in the Preimplantation Mouse $\begin{array}{llll}\text { Embryo. Biology of } & \text { Reproduction, } & \text { 1526-1535. }\end{array}$ http://dx.doi.org/10.1095/biolreprod62.6.1526

Fleming, T. P., Kwong, W. Y., Porter, R., Ursell, E., Fesenko, I., Wilkins, A., Miller, D.J., Watkins, A. J., \& Eckert, J. J. (2004). The embryo and its future. Biology of Reproduction 71, 1046-1054. http://dx.doi.org/10.1095/biolreprod.104.030957

Fortier, A. L., Lopes, F. L., Darricarrere, N., Martel, J., \& Trasler, J. M. (2008). Superovulation alters the expression of imprinted genes in the midgestation mouse placenta. Human Molecular Genetics,17(11), 1653-1665. http://dx.doi.org/10.1093/hmg/ddn055

Fraser, L. R. \& Adeoya-Osiguwa, S. A. (2006). The potential impact of novel investigational compounds on human fertility. Expert Opinion Investigational Drugs,15, 1179-1189. http://dx.doi.org/10.1517/13543784.15.10.1179 
Gnoth, C., Godehardt, E., Frank-Herrmann, P., Friol, K., Tigges, J., \& Freundl, G. (2005). Definition and prevalence of subfertility and infertility. Human Reproduction, 20, 1144-1147. http://dx.doi.org/10.1093/humrep/deh870

Hansen, M., Kurinczuk, J. J., Bower, C., \& Webb, S. (2002). The risk of major birth defects after intracytoplasmicsperm injection and in vitro fertilization. New England Journal of Medicine, 346, 725-730. http://dx.doi.org/10.1056/NEJMoa010035

Introduction: “Reproductive biology” [Introduction]. (2008). Nature Medicine, 14(11), 1166.

Johnson, R. B., \& Onwuegbuzie, A. J. (2004). Mixed methods research: A research paradigm whose time has come. Educational Researcher, 33(7), 14-26. http://dx.doi.org/10.3102/0013189X033007014

Ledger, W.L. (2009). Demographics of infertility. Reproductive BioMedicine Online, 18(suppl. 2), 11-14. http://dx.doi.org/10.1016/S1472-6483(10)60442-7

MacDonald, C. J., Stodel, E. J., Thompson, T-L, \& Casimiro, L. (2009). W(e)Learn: A framework for online interprofessional education. The International Journal of Electronic Healthcare, 5(1), 33-47. Retrieved January 8, 2010 from www.scopus.com.

MacDonald, C.J., Archibald, D., Kellam, H., Sun, R., Stodel, E.J., \& Puddester, D. (2011). Evaluation of online health and wellness resources for healthcare professionals. International Journal of Advanced Corporate Learning, 2(4), 18-23. http://online-journals.org/i-jac/article/view/1659.

MacDonald, C.J. Archibald, D., Puddester, D., Bajnok, I, (2011). Renewal Through Team Development: Experiencing an Emerging Program Design in Interprofessional Education for Healthcare Practitioners. Evaluation and Program Planning Journal, 4(2), 18-23.

Mann, M. R., Lee, S.S., Doherty, A.S., Verona, R.I., Nolen, L.D., Schultz, R. M., et al.(2004). Selective loss of imprinting in the placenta following preimplantation development in culture.Development,131, 3727-3735. http://dx.doi.org/10.1242/dev.01241

Mann, K., Sargeant, J., \& Hill, T. (2009). Knowledge translation in interprofessional education: What difference does interprofessional education make to practice. Learning in Health and Social Care, 8(3), 154-164. http://dx.doi.org/10.1111/j.1473-6861.2008.00207.x

Meads, G. \& Ashcroft, J. (2005). The case for interprofessional collaboration: In health and social care. Malden, MA: Blackwell. http://dx.doi.org/10.1002/9780470776308

Nair, P. (2008). As IVF becomes more common, some concerns remain. Nature Medicine, 14, 1171http://dx.doi.org/10.1038/nm1108-1171Natale, D.R., Paliga, A.J., Beier, F., D'Souza, S.J., \& Watson, A.J. (2004). p38 MAPK signaling during murine preimplantation development. Developmental Biology,268, 76-88. http://dx.doi.org/10.1016/j.ydbio.2003.12.011McMillan, J.H. \& Wergin, J.F. (2006). Understanding and evaluating educational research. Upper Saddle River, NJ: Pearson Education Inc 
Oandasan, I., D’Amour, D., Zwarenstein, M., Barker, K., Purden, M., Beaulieu, M., Reeves, S., Nasmith, L., Bosco, C., Ginsburg, L., \& Tregunno, D. (2004). Interdisciplinary education for collaborative, patient-centred practice. Ottawa: Health Canada.

Pluye, P., Gagnon, M-P., Griffiths, F., \& Johnson-Lafleur, J. (2009). A scoring system for appraising mixed methods research and concomitantly appraising qualitative, quantitative and mixed methods primary studies in mixed studies reviews. International Journal of Nursing Studies, 46(4), 529-546. http://dx.doi.org/10.1016/j.ijnurstu.2009.01.009

Puddester, D., MacDonald, C.J., Archibald, D., Sun, R., \& Stodel, E.J. (2010). Caring for physicians and other healthcare professionals: Needs assessments for eCurricula on physician and workplace health. International Journal on Advances in Life Sciences, 2(1\&2), 63-72.

Salomon, G. \& Perkins, D.N. (1998). Individual and social aspects of learning. Review of Research in Education, 23, 1-24. http://dx.doi.org/10.2307/1167286

Sutcliffe, A.G. \&Ludwig, M. (2007). Outcome of assisted reproduction. Lancet, 370, 351-359. http://dx.doi.org/10.1016/S0140-6736(07)60456-5

Wen, S.W., Yang, Q., Garner, P., Fraser, W., Olatunbosun, O., Nimrod, C., et al. (2006). Selective serotonin reuptake inhibitors and adverse pregnancy outcomes. American Journal of Obstetrics and Gynecology,194,961-966. http://dx.doi.org/10.1016/j.ajog.2006.02.019

\section{Appendix A: Focus Group Questions for the Trainees}

\section{REDIH Training Program Focus Group Questions: TRAINEES}

Hello/introductions

We appreciate you taking the time to be interviewed today. The purpose of this interview is to obtain information on the topics and content of the modules you feel you need and want in order to obtain your long and short term goals in the REDIH Training Program in human or animal reproduction and development, reproductive health, or reproductive technology. The information you provide will be passed on to the content developers to help them organize the content and delivery of the REDIH Training Program.

1. In the needs analysis you mentioned you were not clear about the objectives and expectations of the REDIH program. Do you have a better understanding of the objectives and expectations now?

2. Can you describe your overall experience in the REDIH program to date?

3. In the needs analysis you mentioned that you did not always have enough input into the group discussions? Do you feel you participated more this time?

4. Did you have enough opportunity to interact with the mentors during this REDIH session? Can you think of activities either structured or unstructured for more interaction?

5. How did you find the content of the workshops during this REDIH session? 


\section{Macrothink}

Journal of Studies in Education

ISSN 2162-6952

2012, Vol. 2, No. 1

6. In the needs analysis you mentioned that the workshops were too long. How did you find them this time round?

7. Have you had the opportunity to use any of the information presented during the January REDIH session in your work environment?

8. What has been the most satisfying or rewarding aspect of the REDIH program so far?8. What has been the least satisfying aspect of the REDIH program so far?

9. In your estimation, what changes should be made to the REDIH program?

Thank you for your time!

\section{Appendix B: Training Module Assessment Survey}

In this survey we are gathering information that will be useful in modifying and improving the module you just completed. Your personal appraisal of this module will provide valuable information about how effective the module has been, and what may be needed to improve it in the future. All responses will remain anonymous and will be pooled for analysis. Please identify the module below and complete the survey with reference to this module:

Name of the

Module:

Date of Module:

Module Facilitator:

1. My training level (e.g., M.Sc student, Ph.D. student, postdoctoral fellow):

\section{Gender:}

O Female O Male

\section{Age range:}

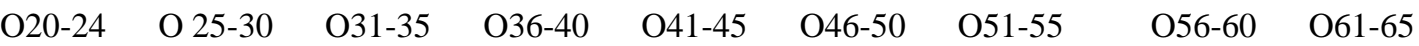

\section{My Education background: (Please check off all that apply)}
$\square$ Biology
$\square$ Biochemistry
$\square$ Health Sciences
$\square$ Chemistry
$\square$ Animal Science
$\square$ Medicine
$\square$ Genetics
$\square$ Cell Biology
$\square$ Molecular Biology
$\square$ Physiology
$\square$ Pharmacology
$\square$ Clinical Epidemiology/Population Health
$\square$ Other: (please specify)

\section{My degree includes:}

$\square$ Undergraduate degree $\quad \square$ Masters Degree $\quad \square$ Ph.D. $\quad \square \mathrm{MD} \quad \square$ DVM 


\section{Why did you participate in this module? (Please check off all that apply) \\ $\square$ Interesting topic $\square$ Professional Development $\quad \square$ Promotes hands-on science \\ $\square$ Educational value $\quad \square$ Relevant to future career $\quad \square$ Encourages science awareness \\ $\square$ Required by REDIH Training Program $\quad \square$ Other:}

\section{The length of the module was:}
$\square$ Too long
$\square$ Too short
$\square$ Just right

Comments:

\section{When do you anticipate using this material in your presentation?}

$\square$ Next week $\quad \square$ Next month $\quad \square$ Within the year $\quad \square$ In future career

$\square$ Not at all - Please explain

\section{Structure}

\section{Never Rarely Sometimes Often Always Undecided}

1) The learning experience took into account my previous knowledge and experiences

2) The learning experience addressed my individual learning style and

$\mathrm{O}$

$\mathrm{O}$

$\mathrm{O}$

$\mathrm{O}$

$\mathrm{O}$

$\mathrm{O}$

$\mathrm{O}$

O preference

3) The learning experience/module was the right length

4) The topic was relevant for the audience

O

$\mathrm{O}$

$\mathrm{O}$

O

O

$\mathrm{O}$ applicable

5) The venue was appropriate for the learning experience

6) The atmosphere was conducive to learning
O

$\mathrm{O}$

$\mathrm{O}$

$\mathrm{O}$
O

O

$\mathrm{O}$

O

$\mathrm{O}$

O

O

O

$\mathrm{O}$

O

$\mathrm{O}$

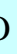


7) The learning experience was well planned

$\mathrm{O}$

$\mathrm{O}$

$\mathrm{O}$ 2012, Vol. 2, No. 1

8) The learning experience was well organized

$\mathrm{O}$

9) My opinions were respected

$\mathrm{O}$

$\mathrm{O}$

10) Content, exercises, and activities aligned with the learning objectives

$\mathrm{O}$

$\mathrm{O}$
$\mathrm{O} \quad \mathrm{O}$

$\mathrm{O}$

$\mathrm{O}$

$\mathrm{O}$
$\mathrm{O}$

$\mathrm{O}$

$\mathrm{O}$

$\mathrm{O}$

$\mathrm{O}$

$\mathrm{O}$

$\mathrm{O}$

$\mathrm{O}$

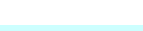

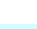

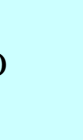


10. Content

\section{\begin{tabular}{lllll|c} 
Never Rarely & Sometimes & Often & Always & Undecided & $\begin{array}{c}\text { Not } \\
\text { applicable }\end{array}$
\end{tabular}}

1) The content was relevant to my professional interests and $\mathrm{O}$
$\mathrm{O}$

$\mathrm{O}$

$\mathrm{O}$

$\mathrm{O}$ needs

2) The content was of appropriate depth and

$\mathrm{O}$

$\mathrm{O}$

$\mathrm{O}$

$\mathrm{O}$

$\mathrm{O}$

O

$\mathrm{O}$

$\mathrm{O}$

$\mathrm{O}$

$\mathrm{O}$

$\mathrm{O}$

$\mathrm{O}$

$\mathrm{O}$

3) The content was appropriate for my knowledge level

4) The learning objectives were clear

5) The content included relevant policies and $\mathrm{O}$

$\mathrm{O}$

$\mathrm{O}$

$\mathrm{O}$

$\mathrm{O}$

$\mathrm{O}$

$\mathrm{O}$

$\mathrm{O}$

regulations

6) The content

comprised a balance of

$\mathrm{O}$

$\mathrm{O}$

$\mathrm{O}$

$\mathrm{O}$

O

$\mathrm{O}$

$\mathrm{O}$

$\mathrm{O}$

theory and practice

7) The content included information applicable and adaptable to new

$\mathrm{O}$

$\mathrm{O}$

$\mathrm{O}$

$\mathrm{O}$

$\mathrm{O}$

$\mathrm{O}$

$\mathrm{O}$ 


\section{Media}

\section{Never Rarely Sometimes Often Always Undecided}

1) The facilitator(s)

was/were knowledgeable

$\mathrm{O}$

$\mathrm{O}$

$\mathrm{O}$

$\mathrm{O}$

$\mathrm{O}$

O about the topic

2) The facilitator(s) had relevant experience
$\mathrm{O}$

O

$\mathrm{O}$

$\mathrm{O}$

$\mathrm{O}$

$\mathrm{O}$

3) The facilitator(s) communicated the information effectively

4) The facilitators(s) challenged and supported

$\mathrm{O}$

$\mathrm{O}$

$\mathrm{O}$

$\mathrm{O}$

$\mathrm{O}$

$\mathrm{O}$

my ideas and research

5) The learning activities contributed to achieving the learning objectives

6) The learning activities were engaging

$\mathrm{O}$

$\mathrm{O}$

O

$\mathrm{O}$

$\mathrm{O}$

$\mathrm{O}$

7) The learning activities reflected situations encountered in the O O

$\mathrm{O}$

$\mathrm{O}$

$\mathrm{O}$

$\mathrm{O}$ workplace
$\mathrm{O}$

$\mathrm{O}$

$\mathrm{O}$

O

$\mathrm{O}$

Not applicable

$\mathrm{O}$

(

$\mathrm{O}$

$\mathrm{O}$

O

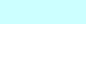

O

8) The learning activities

$\mathrm{O}$

$\mathrm{O}$

$\mathrm{O}$

9) Opportunities for critical thinking were provided
10) Opportunities for self reflection were provided

11) Learning activities

include realistically

complex tasks which are

similar to those I face in

the workplace
O

$\mathrm{O}$

O O

$\mathrm{O}$

$\mathrm{O}$

O

$\mathrm{O}$

O

$\mathrm{O}$

$\mathrm{O}$

$\mathrm{O}$

$\mathrm{O}$ 


\section{Service}

\section{Never Rarely Sometimes Often Always Undecided $\begin{gathered}\text { Not } \\ \text { applicable }\end{gathered}$}

1) The facilitator(s)

provided useful feedback

$\mathrm{O} \quad \mathrm{O}$

$\mathrm{O}$

$\mathrm{O}$

$\mathrm{O}$

$\mathrm{O}$

2) I was provided with and/or made aware of useful tools and

$\mathrm{O} \quad \mathrm{O}$

$\mathrm{O}$

$\mathrm{O}$

$\mathrm{O}$

$\mathrm{O}$

O resources

3) The facilitator(s) were responsive to the $\mathrm{O}$
$\mathrm{O}$

$\mathrm{O}$

$\mathrm{O}$

$\mathrm{O}$

O

$\mathrm{O}$

learners' needs

4) Suggestions and complaints were quickly responded to by

$\mathrm{O}$

$\mathrm{O}$

$\mathrm{O}$

$\mathrm{O}$

O

$\mathrm{O}$

$\mathrm{O}$

facilitators

5) Readings were relevant

$\mathrm{O}$

$\mathrm{O}$

$\mathrm{O}$

$\mathrm{O}$

O

$\mathrm{O}$

$\mathrm{O}$

$\mathrm{O}$

O

relevant and applicable

$\mathrm{O}$

$\mathrm{O}$

$\mathrm{O} \quad \mathrm{O}$

$\mathrm{O}$

$\mathrm{O}$

$\mathrm{O}$

$\mathrm{O}$

$\mathrm{O}$

$\mathrm{O}$ authentic

$\mathrm{O}$

$\mathrm{O}$

$\mathrm{O}$

$\mathrm{O}$

$\mathrm{O}$

$\mathrm{O}$

$\mathrm{O}$ of my learning objectives 


\section{Outcomes}

\begin{tabular}{|c|c|c|c|c|c|c|}
\hline $\begin{array}{c}\text { As a result of this learning } \\
\text { experience: }\end{array}$ & $\begin{array}{l}\text { Strongly } \\
\text { disagree }\end{array}$ & Disagree & Agree & $\begin{array}{c}\text { Strongly } \\
\text { agree }\end{array}$ & Undecided & $\begin{array}{c}\text { Not } \\
\text { applicable }\end{array}$ \\
\hline 1) I understand new principles & $\mathrm{O}$ & $\mathrm{O}$ & $\mathrm{O}$ & $\mathrm{O}$ & $\mathrm{O}$ & $\mathrm{O}$ \\
\hline $\begin{array}{l}\text { 2) I have gained new } \\
\text { knowledge }\end{array}$ & $\mathrm{O}$ & $\mathrm{O}$ & $\mathrm{O}$ & $\mathrm{O}$ & $\mathrm{O}$ & $\mathrm{O}$ \\
\hline $\begin{array}{l}\text { 3) I have acquired proficiency } \\
\text { in new techniques }\end{array}$ & $\mathrm{O}$ & $\mathrm{O}$ & $\mathrm{O}$ & $\mathrm{O}$ & $\mathrm{O}$ & $\mathrm{O}$ \\
\hline 4) I have developed new skills & $\mathrm{O}$ & $\mathrm{O}$ & $\mathrm{O}$ & $\mathrm{O}$ & $\mathrm{O}$ & $\mathrm{O}$ \\
\hline $\begin{array}{l}\text { 5) I will apply new skills in the } \\
\text { workplace }\end{array}$ & $\mathrm{O}$ & $\mathrm{O}$ & $\mathrm{O}$ & $\mathrm{O}$ & $\mathrm{O}$ & $\mathrm{O}$ \\
\hline $\begin{array}{l}\text { 6) I will apply new knowledge } \\
\text { in the workplace }\end{array}$ & $\mathrm{O}$ & $\mathrm{O}$ & $\mathrm{O}$ & $\mathrm{O}$ & $\mathrm{O}$ & $\mathrm{O}$ \\
\hline $\begin{array}{l}\text { 7) I will initiate new ideas } \\
\text { and/or projects }\end{array}$ & $\mathrm{O}$ & $\mathrm{O}$ & $\mathrm{O}$ & $\mathrm{O}$ & $\mathrm{O}$ & $\mathrm{O}$ \\
\hline $\begin{array}{l}\text { 8) I will share new knowledge } \\
\text { with colleagues }\end{array}$ & $\mathrm{O}$ & $\mathrm{O}$ & $\mathrm{O}$ & $\mathrm{O}$ & $\mathrm{O}$ & $\mathrm{O}$ \\
\hline $\begin{array}{l}\text { 9) I will share new resources } \\
\text { with colleagues }\end{array}$ & $\mathrm{O}$ & $\mathrm{O}$ & $\mathrm{O}$ & $\mathrm{O}$ & $\mathrm{O}$ & $\mathrm{O}$ \\
\hline $\begin{array}{l}\text { 10) My current training } \\
\text { environment will benefit from } \\
\text { my new knowledge }\end{array}$ & $\mathrm{O}$ & $\mathrm{O}$ & $\mathrm{O}$ & $\mathrm{O}$ & $\mathrm{O}$ & $\mathrm{O}$ \\
\hline $\begin{array}{l}\text { 11) My future employer will } \\
\text { benefit from my new } \\
\text { knowledge }\end{array}$ & $\mathrm{O}$ & $\mathrm{O}$ & $\mathrm{O}$ & $\mathrm{O}$ & $\mathrm{O}$ & $\mathrm{O}$ \\
\hline $\begin{array}{l}\text { 12) I have a sense of personal } \\
\text { achievement and satisfaction }\end{array}$ & $\mathrm{O}$ & $\mathrm{O}$ & $\mathrm{O}$ & $\mathrm{O}$ & $\mathrm{O}$ & $\mathrm{O}$ \\
\hline $\begin{array}{l}\text { 13) I learned new policies and } \\
\text { regulations I will use in } \\
\text { practice }\end{array}$ & $\mathrm{O}$ & $\mathrm{O}$ & $\mathrm{O}$ & $\mathrm{O}$ & $\mathrm{O}$ & $\mathrm{O}$ \\
\hline $\begin{array}{l}\text { 14) I will use the knowledge } \\
\text { and skills I learned in this } \\
\text { module in my work/research } \\
\text { situation }\end{array}$ & $\mathrm{O}$ & $\mathrm{O}$ & $\mathrm{O}$ & $\mathrm{O}$ & $\mathrm{O}$ & $\mathrm{O}$ \\
\hline
\end{tabular}


14. The most valuable aspect of the module was:

15. The module could be improved by:

16. Additional comments 